\title{
IMPACTOS DA CRISE FINANCEIRA INTERNACIONAL E DA INFLUENZA A SOBRE AS EXPORTAÇÕES BRASILEIRAS DE CARNE SUÍNA ${ }^{1}$
}

\author{
Marcelo Dias Paes Ferreira ${ }^{2}$ \\ Lucas Oliveira de Sousa ${ }^{3}$ \\ Leonardo Bornacki de Mattos ${ }^{4}$ \\ Antonio Carvalho Campos ${ }^{5}$
}

\begin{abstract}
Resumo: Os choques internacionais da última década podem ter afetado as exportações brasileiras de carne suína, assim, o objetivo desse trabalho foi analisar o efeito desses choques. Dá-se ênfase aos choques mais recentes como a crise econômica internacional e a influenza A (H1N1). Analisou-se o impacto sobre os preços de exportação e as quantidades exportadas de carne suína para os dois principais mercados de destino: Rússia e Hong Kong. A teoria do comércio internacional foi utilizada como marco teórico e a análise de intervenção forneceu o suporte metodológico. Constatou-se que as quantidades exportadas para Rússia não foram afetadas pelos recentes choques internacionais, enquanto os preços de exportação foram negativamente afetados pelo efeito transitório da crise. Para Hong Kong, os resultados indicam que o efeito transitório da crise foi negativo tanto para a quantidade exportada quanto para os preços de exportação, já a influenza A (H1N1) afetou negativamente apenas as quantidades exportadas.
\end{abstract}

Palvras-chave: Choques internacionais, Comércio internacional, Análise de intervenção.

Recebido em: 17/11/2010. Aceito em: 15/02/2011.

2 Mestrando em economia aplicada, Universidade Federal de Viçosa, Departamento de Economia Rural. E-mail: marcelo_dpf@yahoo.com.br.

3 Mestrando em economia aplicada, Universidade Federal de Viçosa, Departamento de Economia Rural. E-mail: lucas.agronegocio@gmail.com.

4 D.S. em economia aplicada pela Universidade Federal de Viçosa. Professor adjunto do Departamento de Economia Rural, Universidade Federal de Viçosa. E-mail: lbmattos@ufv.br.

5 Ph.D. em economia agrícola pela Oklahoma State University (USA). Professor titular do Departamento de Economia Rural, Universidade Federal de Viçosa. E-mail: accampos@ufv.br. 


\begin{abstract}
The Brazilian pork exports have been affected by several shocks on the 2000s. This paper aimed to analyze these shocks. The focus of this papers are the main international shocks on the last years: the international economics crisis and de influenza A (H1N1). Analyses were made over the main Brazilian pork exports destinations: Russia and Hong Kong. The theory of international trade was used as a theoretical framework and analysis of intervention provided methodological support. The results show that the quantum exported to Russia has not been affected by the recent shocks. However the prices was negatively affected by crisis in the short term. The quantum exported and the exports prices to Hong Kong have been negatively affected by crisis in the short term. The influenza also has the negative impact over quantum exported to Hong Kong.
\end{abstract}

Keywords: International shocks, International trade, Intervention analyses.

\title{
1. Introdução
}

O setor suinícola brasileiro é importante para a pauta de exportações do agronegócio. No ano de 2008, o Brasil exportou cerca de US $\$ 1,36$ bilhões de carne suína in natura, representando $1,9 \%$ das exportações totais do agronegócio e 9,38 \% das exportações de carnes (BRASIL, 2010). Desse montante, figuraram como principais destinos das exportações, em 2008, a Rússia (53,89 \%), Hong Kong, $(13,17 \%$ ) e a Ucrânia (9,38 $\%)$. Os principais estados exportadores de carne suína em termos de quantidade exportada, em 2008, foram Rio Grande do Sul (44,8 \%), Santa Catarina $(31,8 \%)$ e Paraná $(5,9 \%)$ (OTUKI et al., 2009). O Brasil também é um importante exportador mundial desse produto. Segundo United States (2010), em 2009, o país foi o quarto maior exportador de carne suína em volume, com $11,8 \%$ da quantidade exportada mundialmente naquele ano, ficando atrás dos EUA (34,53 \%), União Europeia $(22,87 \%)$ e Canadá $(20,68 \%)$.

Ao longo das décadas de 1990 e 2000, a suinocultura brasileira sofreu diversos choques internacionais de demanda, decorrentes, principalmente, de problemas sanitários. Recentemente, dois eventos são apontados como choques externos de demanda sobre o setor. O primeiro, de caráter 
econômico, foi a crise econômica mundial que se iniciou em setembro de 2008. Segundo Dowbor (2008), a crise se desenvolveu a partir do mercado imobiliário dos EUA, transformando-se em crise econômica, a partir de setembro de 2008, com a quebra do banco estadunidense Lehman Brothers. O comércio mundial foi bastante afetado pela crise em 2009, reduzindo-se cerca de $23 \%$ em relação a 2008 (BNDES, 2009b). Estimativas do FMI (2009), citadas por BNDES (2009a), apontam que o PIB mundial, em 2009, apresentou redução de - $1 \%$ a - 0,5\%.

O segundo choque, de caráter sanitário, foi o surto da influenza A(H1N1), inicialmente denominada "gripe suína", originada no México, em meados de março de 2009. A influenza A (H1N1) é uma doença respiratória viral transmitida de pessoa a pessoa principalmente por via aérea, não sendo transmitida pelo consumo e manuseio de carne suína (BRASIL, 2009). Nenhum embargo foi imposto às exportações brasileiras de carne suína in natura após o aparecimento dos primeiros focos da doença. Contudo, a denominação "gripe suína" gerou protestos dos países exportadores de carne suína, que temiam a diminuição do consumo mundial desse produto, levando a Organização Mundial da Saúde a mudar o nome da doença para influenza A (H1N1) no final de abril de 2009.

Assim, o objetivo deste trabalho foi verificar se e como esses dois choques internacionais afetaram o desempenho das exportações brasileiras de carne suína in natura. Especificamente, pretendeu-se determinar se tais eventos afetaram os preços de exportação e as quantidades exportadas de carne suína in natura para os dois principais mercados brasileiros, Rússia e Hong Kong.

Trabalhos que analisaram efeitos de choques externos sobre o desempenho de setor de carnes são frequentes, principalmente para choques causados por problemas sanitários. Junqueira (2006) constatou que diversos choques sanitários afetaram o desempenho das exportações brasileiras de carne bovina de 1994 a 2006. Alves (2008) identificou sete eventos de caráter sanitário que afetaram o desempenho das exportações brasileiras de frango de 1996 a 2007. Otuki et al. (2009) mostraram que 
os focos de febre aftosa ocorridos no Brasil em 2004 e 2005 aumentaram a volatilidade dos preços recebidos pelos produtores no Brasil. Por fim, Valente et al. (2009) concluíram que os focos de "gripe aviária", em 1997, diminuíram as importações mundiais de carne de frango e aumentaram as importações mundiais de carne bovina e suína. Esses últimos autores também constataram que, para os anos de 2003, 2004 e 2005, os focos de "gripe aviária" afetaram positivamente as importações mundiais de carne de frango e suína e, negativamente, as importações mundiais de carne bovina. Contudo, nenhum estudo foi realizado a fim de determinar o efeito da crise internacional e da Influenza A H1N1 sobre o desempenho das exportações brasileiras de carne suína in natura.

Além desta seção introdutória, faz parte do presente trabalho o referencial teórico, em que é apresentado um modelo econômico de comércio internacional que explica o efeito de choques internacionais sobre o desempenho das exportações de carne suína; a metodologia, em que são apresentados os procedimentos utilizados no modelo de análise de intervenções; os resultados, em que são expostos e discutidos os eventos que afetaram o desempenho das exportações de carne suína; as conclusões; as referências; e um anexo.

\section{Referencial Teórico}

Como base teórica para a análise, utilizou-se o modelo de equilíbrio parcial do mercado internacional proposto por Krugman e Obstfeld (2005). Esse modelo pressupõe concorrência perfeita e que não há custo de transporte e barreiras artificiais ao comércio. Krugman e Obstfeld (2005) construíram o modelo de equilíbrio parcial por meio das derivações das curvas de oferta de exportação e demanda de importação. A Figura 1 ilustra esse modelo para o mercado internacional de carne suína in natura, em que P é o preço unitário da carne suína e Q é a quantidade. Admite-se, por simplificação, que haja apenas dois países comercializando: um país é exportador de carne suína e outro é importador. 
A curva de oferta de exportação, representada por Ox no diagrama do mercado internacional (Figura 1b), é derivada a partir do equilíbrio no país exportador. O preço de equilíbrio no país exportador, na ausência de comércio, é obtido por meio da intersecção das curvas de oferta e demanda, Oe e De, respectivamente, chegando ao preço de equilíbrio Pe (Figura 1a). O país exporta carne suína se o preço no mercado internacional for maior que Pe, formando assim a curva Ox no diagrama do mercado internacional (Figura 1b). A curva de demanda por importação (Dm) é derivada a partir do país importador de maneira análoga à $\mathrm{Ox}$ (Figura 1c). Assim, o preço de equilíbrio no país importador na ausência de comércio seria Pi. O país somente importará carne suína se o preço no mercado internacional for menor que $\mathrm{Pi}$, originando a curva de demanda de importações no diagrama do mercado internacional (Figura 1b). Admitindo-se o comércio entre esses países, prevalecerá um único preço (Pm) de carne suína em ambos os países, alcançado via equilíbrio no mercado internacional, em que será negociada a quantidade Qox $=\mathrm{Qdm}$ de carne suína (Figura 1b). Ao preço Pm, o país exportador consumirá Qde e produzirá Qoe, o país importador consumirá Qdi e produzirá Qoi. A quantidade exportada por um país (Qoe-Qde) será igual à quantidade importada por outro (Qdi - Qoi), que são iguais ao equilíbrio no mercado internacional.

a

b

País Exportador Mercado Internacional

País Importador

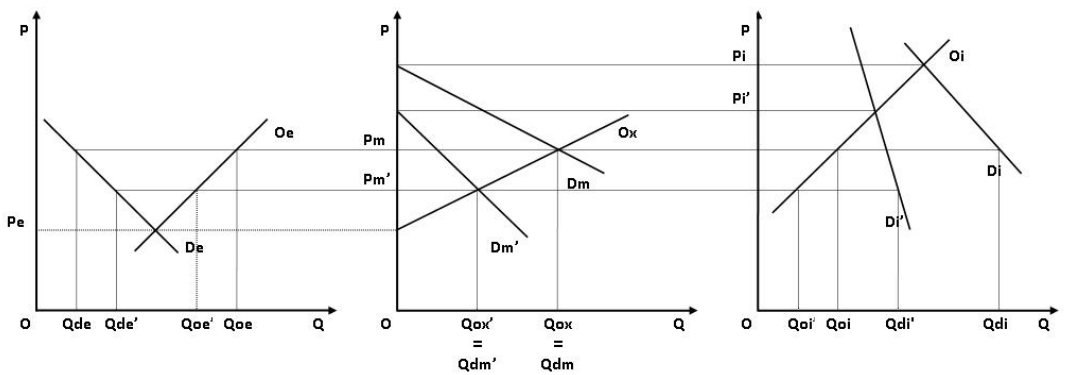

Figura 1: Modelo de equilíbrio parcial do comércio internacional. Fonte: Krugman e Obstfeld (2005). 
Um evento como uma crise internacional pode trazer efeitos sobre o comércio internacional explicados por um modelo de equilíbrio parcial. Admitindo-se que a crise atinja somente o país importador, a queda na renda deslocaria a curva de demanda desse país de Di para Di' ${ }^{6}$, tornando-a mais inclinada. Após esse deslocamento, o preço de equilíbrio, na ausência de comércio no país importador, reduz-se de Pi para Pi' (Figura 1c), deslocando a curva de demanda no mercado internacional de Dm para Dm', diminuindo o preço no mercado internacional de Pm para Pm' (Figura 1b). Com isso, a quantidade negociada no mercado internacional cai para Qox' = Qdm'. O consumo no país importador cai para Qdi' e a quantidade produzida cai para Qoi'. No país exportador, a quantidade consumida aumenta para Qde' e a produzida cai para Qoe'. A quantidade exportada por um país (Qoe' - Qde') será igual à quantidade importada por outro (Qdi' - Qoi'), que é igual ao equilíbrio no mercado internacional.

A influenza A (H1N1) também poderia mudar os gostos e preferências dos consumidores de carne suína no país importador, fazendo com que alguns deixem de comprar carne suína, deslocando a curva de demanda de Di para Di' da mesma forma que a crise, levando ao cenário apresentado anteriormente.

\section{Metodologia}

A análise de séries temporais de variáveis econômicas realizada por meio da metodologia de modelos univariados da classe ARIMA, também conhecido como metodologia de Box e Jenkins, utiliza as informações contidas apenas na série analisada. A versão mais completa desses modelos, denominada SARIMA, acrescenta a análise de termos sazonais. Podem ser incluídas, contudo, outras variáveis aos modelos SARIMA. Quando as variáveis incluídas são quantitativas, como nível de renda, emprego etc., tem-se o modelo de função de transferência. Quando as variáveis incluídas são binárias, cujo objetivo é captar o efeito da ocorrência

6 Isso ocorre por que admite-se que carne suína in natura é um bem normal ou superior. 
de determinado evento, como greves, crises etc., tem-se o modelo de intervenção. Umas das críticas ao modelo ARIMA e suas derivações é que não se baseiam em nenhuma teoria econômica. Entretanto, o modelo de função de transferência e a análise de intervenção agregam teoria econômica aos modelos da classe ARIMA.

Para os objetivos propostos neste trabalho, foram utilizados os modelos de intervenção. Segundo Morettin e Toloi (2004), a construção de um modelo de intervenção deve ser precedida da identificação de um modelo sazonal, autorregressivo, integrado e de médias móveis - SARIMA. Este modelo, por sua vez, exige a identificação da ordem de integração das séries temporais. Para testar a estacionaridade das séries, utilizou-se o teste Augmented Dickey-Fuller (Dickey-Fuller Aumentando - ADF) ${ }^{7}$. Para identificar os componentes de médias móveis (MA) e autorregressivos (AR), utilizou-se o método de identificação de Box e Jenkins, em que a análise da Função de Autocorrelação (FAC) e da Função de Autocorrelação Parcial (FACP) indica os componentes MA e AR, respectivamente, a serem utilizados no modelo (LÜTKEPOHL, 2004: 33-40). Os componentes MA e AR sazonais também são obtidos por meio da significância estatística da FAC e da FACP nas defasagens sazonais $(12,24,36 \ldots)$.

\subsection{Análise de intervenção}

A análise de intervenção modela a ocorrência de eventos que afetam o comportamento da série por meio de variáveis dummies. Normalmente, esses eventos aparecem na série temporal como observações discrepantes, também denominadas outliers. Dos quatro tipos de especificação de outliers (MORETTIN; TOLOI, 2004), optou-se pelo Additive Outliers (AO), pois esta especificação é estimada de forma simples, é linear nos parâmetros e vem sendo utilizada em trabalhos recentes $^{8}$. As intervenções ainda podem ser divididas em pulse ou step

\footnotetext{
Os procedimentos do teste ADF estão descritos em Enders (1995), páginas 221 a 235, e Lütkepohl (2004), páginas 54 a 57.

8 Por exemplo, em Junqueira (2006) e Alves (2008).
} 
(MORETTIN; TOLOI, 2004). A intervenção do tipo pulse é usada para representar eventos que mudam a série apenas no momento em que ocorre, ou seja, a variável assume valor 1 no período referente ao evento e 0 para os demais períodos. A do tipo step é aquela que muda o comportamento da série de maneira permanente, ou seja, a variável assume valor 0 em períodos anteriores ao evento e 1 após o evento.

Para esse trabalho, o modelo de intervenção pode ser assim representado:

$$
X_{i, j, t}=\sum_{1}^{p} \phi_{p} X_{i, j, t-p}+\sum_{1}^{q} \gamma_{q} M_{i, j, t-q}+\sum_{1}^{w} \omega_{w} I N T_{w}+\varepsilon_{t}
$$

em que $X_{i, j, t}$ é a variável a ser analisada, com i representando o tipo de série (quantidade exportada de carne suína in natura, em kg, ou preço de exportação em US\$/kg pelo Brasil), j representando o país de destino (Rússia ou Hong Kong ${ }^{9}$ ) e t representando a série no instante t; $X_{i, j, t-p}$ é o componente autoregressivo (AR), com p representando a ordem dos componentes AR identificados; $\phi_{p}$ representa os coeficientes dos componentes AR; $\quad$ é o componente de média móvel (MA) identificado, com q representando a ordem dos componentes MA; $\gamma_{q}$ representa os coeficientes dos componentes MA; representa as w intervenções (eventos); $\omega_{w}$ os respectivos coeficientes; e representa um termo de erro de ruído branco. Se uma das variáveis representadas por não for estacionária, ela deverá ser diferenciada tantas vezes quantas forem necessárias para torná-la estacionária.

O Quadro 1 mostra as intervenções utilizadas neste trabalho, divididas entre aquelas que foram consideradas para os dois países, as consideradas

\footnotetext{
As exportações de carne suína para a Ucrânia não foram consideradas devido a carência de dados para obter uma série temporal adequada à metodologia usada, visto que as exportações para a Ucrânia tiveram início em 2003 e não foram contínuas.
} 
somente para a Rússia e aquelas utilizadas exclusivamente para Hong Kong. A intervenção referente à crise foi dividida em dois componentes, um de efeito transitório e outro de efeito permanente, a fim de observar como foi o efeito imediato da crise, e se esse efeito persistiu ao longo do tempo. Apesar de a recente crise econômica ter se iniciado na segunda quinzena de setembro de 2008, sua manifestação só pode ser observada nas estatísticas do mês seguinte, haja vista que boa parte das transações referentes ao mês de setembro já haviam sido efetuadas. Desta forma, o mês considerado como início da crise foi outubro de 2008. O mesmo raciocínio corrobora a escolha do mês de abril de 2009 como o mês de início da intervenção referente à influenza $\mathrm{A}(\mathrm{H} 1 \mathrm{~N} 1)$, pois este problema sanitário se tornou conhecido na segunda quinzena de março de 2009. O motivo da diferença de duração do efeito permanente da crise para Rússia e Hong Kong vem do fato de o primeiro país ter apresentado taxas de crescimento muito baixas da renda nacional no quarto trimestre de 2008 e no primeiro trimestre de 2009, (BNDES, 2009a). Por Hong Kong estar atrelada à economia chinesa, que apresentou crescimento relevante no primeiro trimestre de 2009 , considerou-se que a crise tenha atingido aquele mercado somente no quarto trimestre de 2008.

Outras intervenções foram introduzidas no modelo econométrico para agregar o efeito de outros eventos sobre as séries. A inclusão desses últimos eventos foi importante no sentido de retirar o efeito que observações discrepantes associadas a esses eventos teriam sobre a estimação dos parâmetros da crise e da influenza A (H1N1). A identificação dessas intervenções baseou-se, em parte, nos trabalhos de Junqueira (2006) e Alves (2008). Nos modelos estimados para a Rússia, foram incluídas as intervenções que constam na segunda parte do Quadro 1, e nos modelos estimados para Hong Kong, foram utilizadas as intervenções contidas na terceira parte do Quadro 1. 


\section{Quadro 1 - Intervenções consideradas para a análise de desempenho das exportações brasileiras de carne suína in natura para a Rússia e Hong Kong}

\begin{tabular}{|c|c|c|c|c|}
\hline & Código & Evento & Período & Tipo $^{10}$ \\
\hline \multirow{6}{*}{ 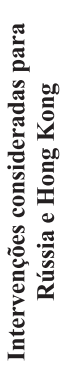 } & INT9_02 & Desvalorização cambial & Setembro de 2002. & $\mathrm{P}$ \\
\hline & INT8_04 & Ocorrência de febre aftosa no PA e AM & Agosto de2004 & $\mathrm{P}$ \\
\hline & INT11_05 & Ocorrência de febre aftosa no PR e MS & Novembro de $2005^{11}$ & $\mathrm{P}$ \\
\hline & CRISE_T & Efeito transitório da crise & $\begin{array}{c}\text { De outubro de } 2008 \text { a março } \\
\text { de } 2009 \text { para a Rússia e de } \\
\text { outubro a dezembro de } 2008 \\
\text { para Hong Kong }\end{array}$ & $\mathrm{P}$ \\
\hline & CRISE_P & Efeito permanente da crise & A partir de outubro de 2008 & $\mathrm{~S}$ \\
\hline & INFLU09 & Influenza A (H1N1) & De abril a julho de 2009 & $\mathrm{P}$ \\
\hline \multirow{6}{*}{ 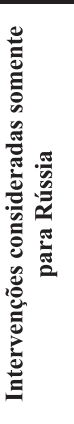 } & INT9_04 & $\begin{array}{l}\text { Embargo Russo à carne suína brasileira } \\
\text { devido ao foco de aftosa em agosto de } \\
2004\end{array}$ & Setembro de 2004 & $\mathrm{P}$ \\
\hline & INT11_04 & $\begin{array}{c}\text { Reabertura do mercado russo à carne } \\
\text { suína de SC }\end{array}$ & Novembro de 2004 & $\mathrm{P}$ \\
\hline & INT3_05 & $\begin{array}{l}\text { Reabertura do mercado russo à carne } \\
\text { suína de SP, MG, GO, PR e RS }\end{array}$ & Março de 2005. & $\mathrm{P}$ \\
\hline & INT12_05 & Gripe aviária na Europa & Dezembro de 2005 & $\mathrm{P}$ \\
\hline & INT4_06 & $\begin{array}{c}\text { Reabertura do mercado russo à carne } \\
\text { suína do RS, após o fechamento em } \\
\text { outubro de } 2005\end{array}$ & Abril de 2006 & $\mathrm{P}$ \\
\hline & INT12_07 & $\begin{array}{l}\text { Reabertura do mercado russo à carne } \\
\text { suína de SC e PR }\end{array}$ & Dezembro de $2007^{12}$ & $\mathrm{P}$ \\
\hline \multirow{5}{*}{ 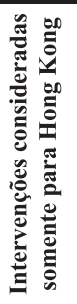 } & INT5_00 & $\begin{array}{l}\text { Declaração do RS e SC como áreas } \\
\text { livres de febre aftosa sem vacinação }\end{array}$ & Maio de 2000 & $\mathrm{P}$ \\
\hline & INT8_00 & Ocorrência de aftosa no RS & Outubro de 2000 & $\mathrm{P}$ \\
\hline & INT5_01 & Ocorrência de febre aftosa no RS & Maio de 2001 & $\mathrm{P}$ \\
\hline & INT10_03 & Gripe aviária no sudeste asiático & Outubro de 2003 & $\mathrm{P}$ \\
\hline & INT8_07 & $\begin{array}{c}\text { Preços elevados de suíno no mercado } \\
\text { Chinês }\end{array}$ & Agosto de 2007 & $\mathrm{P}$ \\
\hline
\end{tabular}

${ }_{10} \mathrm{O}$ "P"significa que a intervenção é do tipo pulse e o "S" significa que a intervenção é do tipo step.

11 Este evento ocorreu na segunda quinzena de outubro de 2005, portanto, considerou-se o mês seguinte para captar a efeito desse evento.

12 A abertura do mercado russo à carne suína procedente de Santa Catarina e Paraná ocorreu em 23 de novembro de 2007 , por ocorrer no final do mês de novembro, a dummy introduzida no modelo foi referente ao mês de dezembro de 2007. 
Marcelo Dias Paes Ferreira, Lucas Oliveira de Sousa,

Leonardo Bornacki de Mattos \& Antonio Carvalho Campos

\subsection{Fontes de dados}

A quantidade das exportações, em quilograma, e o valor das exportações, em dólares americanos, de carne suína in natura ${ }^{13}$ do Brasil para Rússia, de janeiro 2002 a dezembro de 2009, e para Hong Kong, de janeiro de 1999 a dezembro de $2009^{14}$, foram obtidos no sistema AGROSTAT, do Ministério da Agricultura Pecuária e Abastecimento. Os preços de exportação, em dólares por quilograma, foram obtidos dividindo-se o valor exportado pela quantidade no respectivo mês. Foi utilizado o Índice de Preços no Atacado dos Estados Unidos (IPA), obtido no Instituto de Pesquisa Econômica Aplicada, para deflacionar as séries monetárias com base em dezembro de 2009. Assim, trabalhou-se com as séries de Quantidade Exportada para Rússia (QRU), Preço de Exportação para Rússia (PRU), Quantidade Exportada para Hong Kong (QHK) e Preço de Exportação para Hong Kong (PHK). Os gráficos das séries de preços e de quantidades utilizadas nesses trabalhos encontram-se nas Figuras $1 \mathrm{~A}$ e $2 \mathrm{~A}$ do anexo desse trabalho.

\section{Resultados e discussão}

Os resultados do teste ADF (Tabela 1) mostram que a hipótese nula de haver raiz unitária na série QRU é rejeitada ao nível de $1 \%$ de significância, portanto, a série é estacionária. A série PRU não é estacionária ao nível de $5 \%$, contudo, sua primeira diferença, DPRU, é estacionária a $1 \%$. A série QHK é estacionária pelo teste ADF ao nível de $1 \%$ de significância. A equação de teste indica que esta série é estacionária em torno de uma tendência determinística. A tendência que melhor se ajustou à série $\mathrm{QHK}$, pelo critério de maior $\mathrm{R}^{2}$, foi a exponencial.

13 O que é considerada carne suína in natura neste trabalho são animais abatidos exportados em carcaça inteira ou em cortes, podendo ser resfriados ou congelados. Esses produtos possuem os seguintes códigos da Nomenclatura Comum do Mercosul - NCM: 0203.11.00, 0203.12.00, 0203.19.00, 0203.21.00, 0203.22.00 e 0203.29.00.

14 O mês inicial da análise de Hong Kong foi escolhido devido à mudança cambial ocorrida em janeiro de 1999, o que colocaria os dados para aquele mercado no mesmo regime cambial. O mês de janeiro de 2002 foi escolhido para a análise da Rússia, pois, mesmo havendo exportação de carne suína in natura em períodos anteriores, foi a partir de 2002 que as exportações para aquele mercado se consolidaram. A Ucrânia não foi incluída na análise devido à sua série não ser suficientemente longa. 
Assim, utilizou-se o resíduo da regressão de QHK contra a tendência exponencial e uma constante para criar a série quantidade de carne suína in natura exportada para Hong Kong livre de tendência determinística (QHKLTD), que foi utilizada na análise de intervenção para aquele destino. A série PHK não é estacionária a $5 \%$ de significância, contudo, a primeira diferença de série, DPHK, é estacionária a $1 \%$.

Tabela 1 - Teste de raiz unitária ADF para as séries QRU, PRU, DPRU, QHK, PHK e DPHK

\begin{tabular}{cccccc}
\hline \hline Série & Equação de teste & $\begin{array}{c}\text { Número de } \\
\text { defasagens }\end{array}$ & $\begin{array}{c}\text { Estatística } \\
\text { de teste }\end{array}$ & \multicolumn{2}{c}{ Valor crítico } \\
\cline { 5 - 6 } QRU & com const. & 0 & $-5,202$ & $-2,892$ & $-3,501$ \\
PRU & sem const. e sem tend. & 0 & 0,155 & $-1,944$ & $-2,590$ \\
DPRU & sem const. e sem tend. & 0 & $-9,484$ & $-1,944$ & $-2,580$ \\
QHK & com const. e com tend. & 0 & $-8,181$ & $-3,444$ & $-4,030$ \\
PHK & sem const. e sem tend. & 0 & $-0,655$ & $-1,943$ & $-2,583$ \\
DPHK & sem const. e sem tend. & 0 & $-10,979$ & $-1,943$ & $-2,583$ \\
\hline \hline
\end{tabular}

Fonte: Resultados da pesquisa.

A identificação dos componentes MA e AR foi feita a partir dos correlogramas das séries QRU, DPRU, QHKLTD e DPHK. O processo formador da série QRU foi um $\operatorname{ARIMA}(1,0,1)$, dado que a FAC e a FACP são significativas ${ }^{15}$ na primeira defasagem. Poderiam ter sido incluídos outros componentes AR e MA na análise de intervenção para QRU, dado que outras FAC e FACP são significativas. Contudo, adotouse o princípio da parcimônia, evitando o excesso de coeficientes a serem estimados, a diminuição dos graus de liberdade e problemas de multicolinearidade. O processo formador da série DPHK foi um ARIMA(0,1,0), pois nenhuma FAC ou FACP foi significativa e, portanto, não se pode identificar nenhum componente MA ou AR pelo método de Box e Jenkins. A série QHKLTD é um ARIMA(1,0,1), pois tanto a FAC, quanto a FACP, para a primeira defasagem são significativas. A série DPHK não apresentou nenhum coeficiente da FAC ou FACP

${ }_{15}$ O nível de significância adotado foi de $5 \%$ para todas FAC e FACP. 
significativos, tendo a mesma especificação que o modelo da série DPRU. Não foi identificado nenhum componente MA ou AR sazonal para as séries analisadas.

Os resultados da análise de intervenção estão expostos na Tabela 2 onde são apresentados os coeficientes estimados para as séries QRU, DPRU, QHKLTD e DPHK, respectivamente. A hipótese nula de todos os coeficientes, em cada regressão, serem iguais a zero é rejeitada a um nível de significância de $1 \%$ pelo teste $\mathrm{F}$. Os resíduos de todas os modelos possuem características de ruídos brancos, ou seja, não possuem nenhuma FAC ou FACP significativas.

As variáveis que se mostraram significativas a $10 \%$ pelo teste $t$ na análise de intervenção para a quantidade de carne suína in natura exportada do Brasil para a Rússia foram: INT8_04, INT11_05, INT12_07, a constante $\mathrm{C}$, o componente $\mathrm{AR}(1)$ e o componente MA(1) (Tabela 2). O coeficiente de INT8_04 ${ }^{16}$ indica que, devido aos focos de febre aftosa nos estados do Amazonas e Pará, a exportações de carne suína in natura para a Rússia cresceram cerca de 13 mil toneladas. Seria esperado um decréscimo das exportações diante daqueles focos. Provavelmente, temendo dificuldades futuras decorrentes de embargos da Rússia, que ocorreram no mês seguinte (setembro de 2004), os exportadores de carne suína aumentaram e/ou adiantaram as remessas para aquele mercado. Os coeficientes das intervenções INT11_05 e INT_07 indicam, respectivamente, que os focos de febre aftosa de 2005 reduziram as exportações de carne suína para Rússia em cerca de 10,5 mil toneladas e que a reabertura do mercado russo à carne suína produzida no Paraná e Santa Catarina, em dezembro de 2007, elevou as exportações para aquele mercado em cerca de 19 mil toneladas naquele mês. Constata-se também que a crise econômica e a influenza A (H1N1) não afetaram as exportações brasileiras em volume de carne suína para Rússia, uma vez que os coeficientes estimados para CRISE_T, CRISE_P e INFLU09 não são significativos a $10 \%$.

${ }_{16}$ Nenhum trabalho anterior utilizou a abordagem deste trabalho para analisar as intervenções (INT), portanto, os coeficientes dessas variáveis que se mostraram significativos foram brevemente discutidos. 
REVISTA DE ECONOMIA E AGRONEGÓCIO, VOL.9, $N^{o} 1$

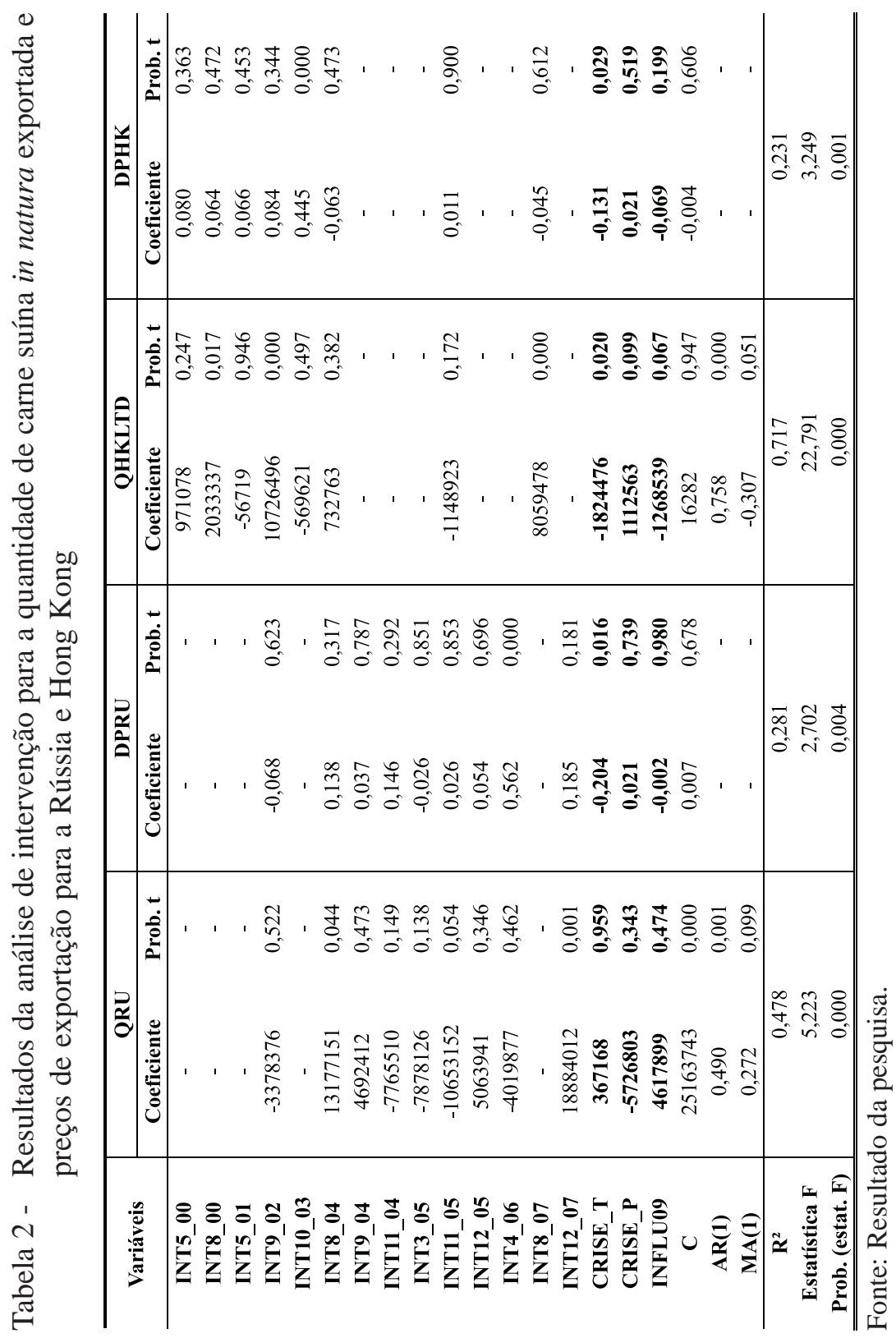


A análise de intervenção para os preços de exportação para Rússia mostra que somente os coeficientes das variáveis INT4_06 e CRISE_T foram significativos a $10 \%$ pelo teste $\mathrm{t}$ (Tabela 2). A reabertura do mercado russo à carne suína proveniente do Rio Grande do Sul, em abril de 2006, elevou os preços de exportação para aquele mercado em cerca de US\$ 0,56/kg naquele mês. O coeficiente da CRISE_T indica que DPRU foi cerca de US\$ 0,20/kg menor devido ao efeito transitório da crise. Uma vez que se utilizou a primeira diferença da série de preços para Rússia, o coeficiente de CRISE_T mostra que ao longo dos seis meses considerados como a crise no curto prazo para aquele país, o preço de exportação (PRU) caiu cerca de US\$1,22/kg. A influenza A (H1N1) não afetou os preços de exportação de carne suína para Rússia, visto que o coeficiente de INFLU09 não é significativo a $10 \%$. A crise não teve efeito permanente sobre os preços de exportação para Rússia, dada a não significância $(10 \%)$ do coeficiente relativo à CRISE_P. Isto indica que o efeito do choque de demanda causado pela crise sobre os preços de exportação para Rússia já havia cessado em dezembro de 2009.

$\mathrm{Na}$ análise de intervenção para quantidade exportada de carne suína para Hong Kong, os coeficientes significativos a $10 \%$ pelo teste $t$ foram os relativos às variáveis INT8_00, INT9_02, INT8_07, CRISE_T, CRISE_P, INFLU09 AR(1) e MA (1) (Tabela 2). O modelo indica que a ocorrência de febre aftosa no Rio Grande do Sul em agosto de 2000 elevou as exportações brasileiras de carne suína para Hong Kong em cerca de 2 mil toneladas. Uma explicação para este aumento pode ser a mesma feita para a intervenção INT8_04 no modelo de quantidade exportada para Rússia, adiantamento de remessas diante do problema sanitário para se antecipar a um possível embargo. O coeficiente da variável INT9_02 indica que a desvalorização cambial, em setembro de 2002, elevou a quantidade exportada de carne suína para Hong Kong em cerca de 10,7 mil toneladas. Os preços altos no mercado chinês, em agosto de 2007, elevaram a quantidade de carne suína exportada para Hong Kong em cerca de 8 mil toneladas. O efeito transitório da crise levou a uma redução nas exportações de carne suína para Hong Kong em cerca de 1,8 mil toneladas por mês, como pode ser observado no 
coeficiente da variável CRISE_T. Contudo, a crise não teve efeito permanente, pois o coeficiente da CRISE_P foi positivo, indicando que, de outubro de 2008 a dezembro de 2009, as exportações mensais de carne suína para Hong Kong foram cerca de 1,1 mil toneladas maiores que antes da crise. Isso indica que as exportações em quantidade começaram a se recuperar. O coeficiente da variável INFLU09 mostra que a influenza $\mathrm{A}(\mathrm{H} 1 \mathrm{~N} 1)$ reduziu a quantidade exportada de carne suína para Hong Kong em cerca de 1,2 mil toneladas por mês. Essa redução na quantidade das exportações para aquele mercado está associada ao fato de a população de Hong Kong ter passado por diversas epidemias de doenças respiratórias nas últimas décadas, especialmente a gripe aviária a partir de 1997, o que pode ter causado receio na população em consumir carne suína e contrair influenza A (H1N1).

$\mathrm{Na}$ análise de intervenção para os preços de exportação de carne suína in natura para Hong Kong, foram significativos a $10 \%$ os coeficientes das variáveis INT10_03 e CRISE_T (Tabela 2). O coeficiente de INT10_03 indica que o preço de exportação para Hong Kong aumentou cerca de US\$ 0,45/kg devido os surtos de gripe aviária na Ásia em 2003. O coeficiente da CRISE_T mostra que o efeito transitório da crise afetou a variável DPHK em US\$ - 0,13/kg, o que significa dizer que, no último trimestre de 2008, o preço de exportação de carne suína do Brasil para Hong Kong caiu cerca de US\$ 0,39/kg. A não significância estatística, ao nível de $10 \%$, do coeficiente de CRISE_P mostra que o choque nos preços já havia cessado em dezembro de 2009, contudo, não é observada uma recuperação. Não foi constado efeito da influenza A (H1N1) sobre os preços de exportação para Hong Kong, dado que o coeficiente de INFLU09 não foi significativo a $10 \%$.

A redução mais expressiva no preço de exportação para o mercado russo teve como consequência a aproximação entre os preços praticados naquele mercado e em Hong Kong. De janeiro de 2004 a setembro de 2008, os preços para Rússia foram, em média, 43,7 \% maiores que os de Hong Kong. Após a crise, de outubro de 2008 a dezembro de 2009, essa margem foi de 15,2 \%. Isso indica que, diante da crise econômica, os 
exportadores brasileiros de carne suína diminuíram mais os preços para a Rússia do que para Hong Kong. A maior queda no preço para Rússia explica por que não houve tanto o efeito transitório quanto permanente da crise sobre a quantidade exportada para aquele país. Os exportadores brasileiros reduziram os preços para não perder o importante mercado russo.

Outra variável que merece destaque é a desvalorização do real em relação ao dólar americano nos meses iniciais da crise. Dados do Ipea (2010) mostram que de setembro de 2008 a março de 2009 a taxa câmbio R \$/ US \$ nominal se desvalorizou, em média, cerca de 3,2 \% ao mês, passando de RS\$1,80/US\$ para RS\$2,31/US\$. Desta forma, a crise não afetou tanto os preços das exportações brasileiras de carne suína in natura visto que essa desvalorização cambial fez com que os preços em dólares caíssem. Diante da crise, o preço pago aos exportadores brasileiros em reais não caiu muito, dado que o efeito da queda do preço em dólar foi compensado, em parte, pela desvalorização da taxa de câmbio.

\section{Conclusões}

O desempenho das exportações brasileiras de carne suína in natura diante da recente crise internacional e da influenza A (H1N1) sofreu impactos distintos em se tratando do mercado de destino. A expectativa, de acordo com a teoria que dá suporte a esta análise, era de que eventos como os supracitados diminuíssem a quantidade exportada e os preços de exportação da carne suína in natura brasileira. Os testes realizados mostraram que, em parte, o modelo teórico estava correto.

Constatou-se que os principais países de destino das exportações brasileiras de carne suína apresentam características distintas, fazendo com que os resultados se refletissem de maneira distinta em cada um. As exportações em quantidade para a Rússia não foram afetadas por nenhum dos eventos analisados de forma direta neste trabalho - a crise e a influenza $\mathrm{A}(\mathrm{H} 1 \mathrm{~N} 1)$. Contudo, os preços de exportação de carne suína 
para aquele mercado se mostraram bastante sensíveis nos meses iniciais da crise, deixando transparecer que, provavelmente, a demanda por carne suína seja inelástica ao preço e à renda no mercado russo. Outra constatação do efeito transitório da crise sobre os preços de exportação para Rússia foi a redução da discriminação de preços que o setor suinícola brasileiro praticava entre os dois principais mercados de exportação.

Mais próximo do modelo teórico proposto, foi o desempenho das exportações de carne suína para Hong Kong diante da crise econômica e da influenza A (H1N1). Por questões históricas, a influenza A (H1N1) reduziu a quantidade de carne suína exportada para aquele país. A crise teve efeito transitório, pois afetou o desempenho das exportações no último trimestre de 2008, entretanto, ao longo de 2009, as quantidades exportadas de carne de suína mostraram recuperação, enquanto não foi observado efeito permanente sobre os preços.

As diferenças entre os dois países na condição de mercados de destino da carne suína brasileira são benéficas, no sentido que, de certa forma, diminuem os riscos da atividade. Contudo, as lideranças do setor suinícola brasileiro deveriam buscar novos mercados, pois assim, os riscos de queda no desempenho das exportações de carne suína in natura diante de choques internacionais diminuiriam. Ao setor público, caberia reforçar ações de prospecção de novos mercados por meio de promoção de missões empresariais, continuar a investir em defesa sanitária e promover a defesa dos interesses do setor em fóruns internacionais para evitar que embargos à importação de carne suína brasileira sejam estabelecidos por motivos injustos.

Algumas questões ainda não respondidas neste trabalho englobam o efeito dos eventos estudados sobre os preços pagos aos produtores e sobre os preços praticados no varejo e atacado brasileiros, bem como sobre a quantidade de carne suína produzida e consumida internamente. $\mathrm{O}$ diferencial de preços entre as exportações de carne suína para Rússia e Hong Kong sugere que a distância pode impactar no preço, portanto, trabalhos que investiguem o papel da distância dos mercados importadores sobre o desempenho do setor suinícola brasileiro são relevantes. Outra 
questão que emerge deste trabalho é determinar a sensibilidade dos preços de exportações e das quantidades exportadas de carne suína à política cambial, à renda dos países importadores e a outras variáveis relevantes.

\title{
Referências
}

\begin{abstract}
ALVES, M. C. Identificação e efeitos das barreiras não-tarifárias às exportações brasileiras de carne de frango. $2008.132 \mathrm{f}$. Dissertação (Mestrado) - Universidade Federal de Viçosa, Viçosa.
\end{abstract}

BNDES. Banco Nacional de Desenvolvimento Econômico e Social. Sinopse Internacional. Disponível em: <http://www.bndes.gov.br/ SiteBNDES/export/sites/default/bndes pt/Galerias/Arquivos/ conhecimento/sinopse intl/SI11.pdf > . Acesso em: 10 jan. 2010. Publicado em: mar. 2009a.

. Sinopse Internacional. Disponível em: $<$ http://www.bndes.gov.br/SiteBNDES/export/sites/default/bndes_pt/ Galerias/Arquivos/conhecimento/sinopse_intl/SI12.pdf >. Acesso em: 10 jan. 2010. Publicado em: set. 2009b.

BRASIL. Ministério da Saúde. Influenza A (H1N1): Perguntas e Respostas. Disponível em: http://portal.saude.gov.br/portal/saude/ profissional/visualizar texto.cfm?idtxt=31267. Acesso em: 14 jan. 2010. Publicado em: 14 out. 2009.

BRASIL. Ministério da Agricultura, Pecuária e Abastecimento. Secretaria de Relações Internacionais do Agronegócio: AgroStat Brasil. Disponível em: 〈http://www.agricultura.gov.br $>$. Acesso em: 09 jan. de 2010.

DOWBOR, Ladislau. A crise financeira sem mistérios: Convergência dos dramas econômicos, sociais e ambientais. Economia Global e Gestão, dez. 2008, vol.13, no.3, p.09-38. ISSN 0873-7444. 
ENDERS, W. Applied Econometric Time Series. Nova York: John Wiley \& Sons, Inc., 1995. 433 p.

IPEA - INSTITUTO DE PESQUISA ECONÔMICA APLICADA. Dados Macroeconômicos e Regionais. Disponível em: <http:// www.ipeadata.gov.br/ipeaweb.dll/ipeadata?991206562>. Acesso em: 15 jan. 2010.

JUNQUEIRA, B. A. Identificação e análise de barreiras nãotarifárias sobre as exportações brasileiras de carne bovina. 2006. 138 f. Dissertação (Mestrado) - Universidade Federal de Viçosa, Viçosa.

KRUGMAN, P. R., OBSTFELD, M. Economia Internacional: teoria e política. Trad de Eliezer Martins Diniz. 6. ed. São Paulo, SP: Pearson Addison Wesley, 2005. 558 p.

MORETTIN, P.A.; TOLOI, C.M.C. Análise de séries temporais. São Paulo: Edgard Blucher, 2004. 535p.

LÜTKEPOHL, H. Univariate Time Series Analysis. In: LÜTKEPOHL, H., KRÄTZIG, M. (Eds.). Applied Time Series Econometrics. Cambridge, UK: Cambridge University Press. 2004. 323 p.

OTUKI, T. F., WEYDMANN, C. L., SEABRA. F. Febre aftosa e volatilidade dos preços do produtor de carne suína. Revista de Economia e Agronegócio, Viçosa, MG, v. 7, n. 2, p. 235-265, 2009.

UNITED STATES. Departament of Agriculture. Foreign Agricultural Service: Production, Supply and Distribution on line. Disponível em: <http:/ /www.fas.usda.gov/psdonline/psdquery.aspx > . Acesso em 10 jan. 2010.

VALENTE, L. C. M., GOMES, M. F. M., CAMPOS, A. C. Impactos da influenza aviária no mercado internacional de carnes. Revista de Economia e Agronegócio, Viçosa, MG, v. 7, n. 3, p. 313-336, 2009. 
Marcelo Dias Paes Ferreira, Lucas Oliveira de Sousa,

Leonardo Bornacki de Mattos \& Antonio Carvalho Campos

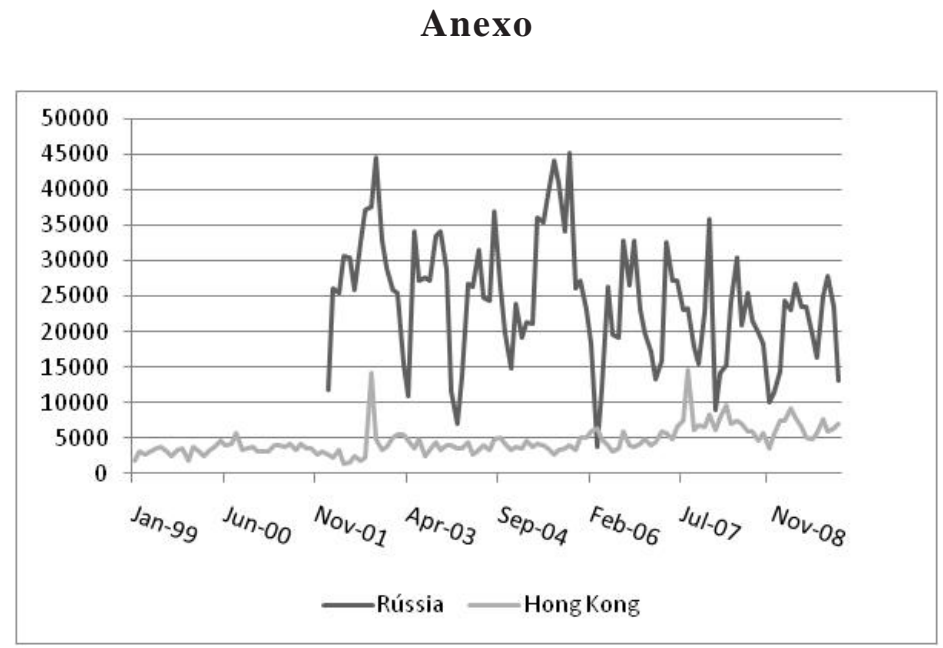

Figura 1A -Quantidade exportada em toneladas de carne suína in natura para a Rússia e para Hong Kong.

Fonte: Brasil (2010)

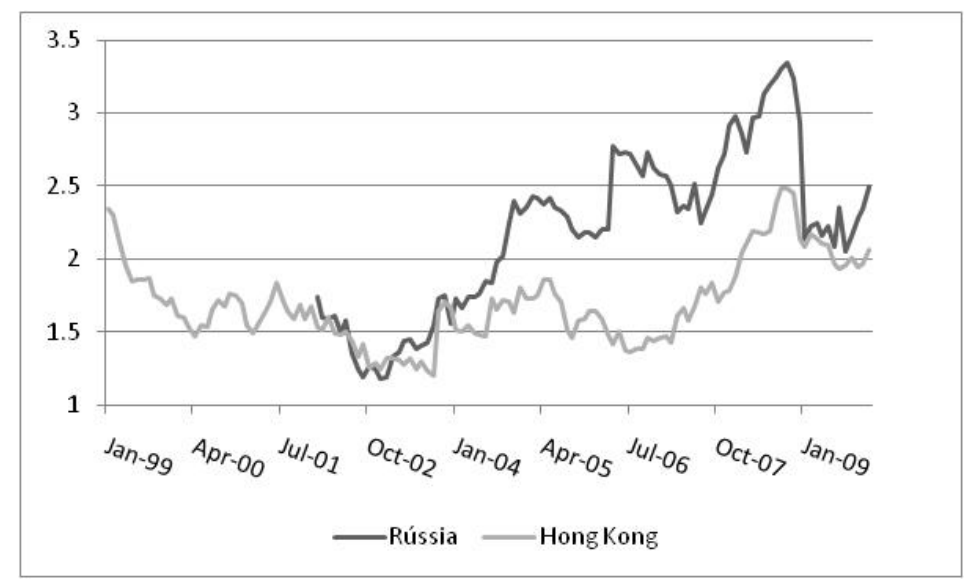

Figura 2A - Preço de exportação de carne suína in natura em US\$/kg para a Rússia e para Hong Kong.

Fonte: Brasil (2010) 
REVISTA DE ECONOMIA E AGRONEGÓCIO, VOL.9, $N^{\circ} 1$ 